\title{
Microstructure and thermal conductivity of Si-Al-C-O fiber bonded ceramics joined to refractory metals
}

\author{
M. C. Vera' ${ }^{1}$, J. Martinez-Fernandez ${ }^{1}$, M. Singh ${ }^{2}$, V. Casalegno ${ }^{3}$, C. Balagna ${ }^{3}$, J. Ramirez-Rico ${ }^{*}$ \\ ${ }^{1}$ Dpto. Fisica de la Materia Condensada-ICMS, Universidad de Sevilla-CSIC, Spain \\ ${ }^{2}$ Ohio Aerospace Institute, Cleveland, OH, USA \\ ${ }^{3}$ Applied Science and Technology Department, Institute of Materials Physics and Engineering, \\ Politecnico di Torino, Italy
}

\begin{abstract}
We explore joining Si-Al-C-O fiber-bonded ceramics to Cu-clad-Mo using an Ag-Ti-Cu brazing alloy. A temperature of $900^{\circ} \mathrm{C}$ and times in the range of 10-20 min are required to obtain sound joints irrespectively of the fiber orientation. The reaction layer is 1-2 $\mu \mathrm{m}$ thick and free of pores and defects. The thermal conductivity of the joined samples is well described considering that the metal and the ceramic are in series for thermal resistance. This implies that the joint is highly conductive and forms an almost perfect thermal interface between the two materials, confirming the quality of the obtained brazing layer.
\end{abstract}

Keywords: silicon carbide; ceramics; thermal conductivity; joining

\section{Introduction}

Fiber bonded ceramics are obtained from hot-pressing polymer derived SiC fibers, which can be made into complex shapes using molds and spacers. Several authors have shown that these materials are competitive with fiber reinforced ceramic matrix composites in terms of high temperature thermal and chemical stability, creep and static fatigue resistance, and thermal conductivity. Some examples of these materials are Si-Ti-C-O [1] and Si-Al-C-O [2] fiber bonded ceramics obtained from Tyranno and Tyranno-SA fibers, respectively.

In most applications fiber bonded ceramics will need to be joined either to other ceramics or metals, especially those that can be used at elevated temperatures. For these reasons, several authors have studied the bonding of silicon carbide (SiC) ceramics to other materials using

\footnotetext{
*Corresponding author - Email: jrr@us.es, Tel: +34 954550936
} 
different approaches [3]. Several authors have successfully used brazing as a method for joining fiber bonded $\mathrm{SiC}$ ceramics to themselves [4].

In this work, we explore the joining of $\mathrm{Si}-\mathrm{Al}-\mathrm{C}-\mathrm{O}$ fiber bonded ceramic materials to $\mathrm{Cu}-\mathrm{Clad}-\mathrm{Mo}$, using Ag-Ti-Cu based active fillers, as previously used to join refractory metals to carbon, carbides and borides $[5,6]$. Since most of the proposed applications are related to thermal management for these systems [7-9], we measure the thermal conductivity of both the bare ceramic as well as the joints. The resulting conductivity can be well explained by considering two material layers in series, confirming that the interfacial resistance of the brazing seam is very low.

\section{Materials and methods}

The fiber-bonded ceramic composite was obtained from Ube Industries (Japan) and is composed of pressed Si-Al-C-O fibers that adopt a polygonal cross section after hot-pressing as shown in Figure 1-a. These are highly crystalline fibers composed mostly of $\beta$-SiC grains with a small amount of unreacted $\mathrm{C}$ at their interfaces (Figure 1-b). The refractory metal was Copper-clad Molybdenum (Climax Specialty Metals, USA) in $1 \mathrm{~mm}$ thick sheets, with a $600 \mu \mathrm{m}$ layer of Mo (>99.95\%) sandwiched between two $200 \mu$ m layers of oxygen-free $\mathrm{Cu}$. Brazing was performed using a single $50 \mu \mathrm{m}$ thick sheet of $\mathrm{Ag}$-Cu-Ti alloy with a liquidus temperature of $815^{\circ} \mathrm{C}$ (Cusil ABA, Morgan Advanced Ceramics, USA). Table 1 shows relevant properties of the materials used in this work.

Table 1. Main room-temperature properties of Cu-clad Mo [10], Cusil-ABA [11] and fiber-bonded $\mathrm{SiC}$ ceramic (data from the manufacturer).

\begin{tabular}{|c|c|c|c|c|c|}
\hline Material & Composition & Density $\left(\mathrm{g}^{\prime} \mathrm{cm}^{-3}\right)$ & $\begin{array}{l}\text { Young modulus } \\
\text { (GPa) }\end{array}$ & $\begin{array}{l}\text { Thermal expansion } \\
\text { coefficient }\left(10^{-6} / \mathrm{K}\right)\end{array}$ & $\begin{array}{l}\text { Thermal } \\
\text { conductivity } \\
\left(\mathbf{W m}^{-1} \mathrm{~K}^{-1}\right)\end{array}$ \\
\hline Cu-Clad Mo & $\begin{array}{l}60 \text { vol. \% Mo } \\
\mathrm{Cu}\end{array}$ & 9.55 & 283,5 & 11.6 & $200-250$ \\
\hline Cusil-ABA & $\begin{array}{l}63 \% \mathrm{Ag} \\
35,25 \% \mathrm{Cu} \\
1,75 \% \mathrm{Ti} \text { (wt. } \\
\%)\end{array}$ & & 130 & 18.5 & 180 \\
\hline $\begin{array}{l}\text { Fiber-bonded } \\
\text { ceramic }\end{array}$ & $\begin{array}{l}88 \text { vol. \% SiC } \\
\text { C }\end{array}$ & 3.10 & 300 & 3.20 & $\begin{array}{l}71,5 \text { (in-plane) } \\
52,2 \text { (through } \\
\text { thickness) }\end{array}$ \\
\hline
\end{tabular}


Joining was performed by heating over the liquidus temperature of the brazing alloy under argon at a nominal pressure of 2 bar in a tube furnace. Heating rate was $15^{\circ} \mathrm{C} / \mathrm{min}$ up to $720^{\circ} \mathrm{C}$, held for 90 minutes to homogenize the temperature across the interface, and then at $5{ }^{\circ} \mathrm{C} / \mathrm{min}$ up to 900 ${ }^{\circ} \mathrm{C}$, maintained for a time $t_{B}$ (10 or 20 minutes). Since fiber bonded $\mathrm{SiC}$ is transversely isotropic, the effect of fiber orientation was explored by producing joints in planes parallel or perpendicular to the ceramic fiber mats.

Thermal diffusivity was measured using the Laser-Flash technique (LFA1600 from Linseis, Germany) in vacuum. Samples were $10 \times 10 \mathrm{~mm}^{2}$. In the case of the ceramic, diffusivity was measured across two directions, one parallel and the other perpendicular to the pressing direction. In the case of the joint, the orientation was such that the ceramic's pressing direction is parallel to the braze. This orientation shows highest conductivity and is the most difficult to join, as the fiber ends are perpendicular to the brazing seam. Thermal conductivity $k(T)$ was calculated from thermal diffusivity $\alpha(T)$ using:

$$
k(T)=\rho \alpha(T) C_{p}(T)
$$

Where $\rho$ is the density and $C_{p}(T)$ is the specific heat capacity. Heat capacity for $\mathrm{SiC}$ was interpolated following Snead et al. [12], while that of Cu-Clad-Mo was taken as $0.313 \mathrm{~J} \mathrm{~g} \mathrm{~g}^{-1} \mathrm{~K}^{-1}$ at $150^{\circ} \mathrm{C}[10]$ and considered constant for the studied temperature range.

\section{Results and discussion}

Figure 1-c shows an example of one of the joints obtained in this work, for the case of $t_{B}=20 \mathrm{~min}$. In the central region the brazing alloy can be observed (marked with a rectangle), with lighter contrast corresponding to Ag-rich areas. No pores or defects can be seen in the metal-alloy interface, as Ag enrichment of the $\mathrm{Cu}$ cladding helps improve its ductility thus minimizing stresses due to thermal mismatch, as shown in joints of Cu-clad-Mo to C-C fiber composites [13]. A closer inspection of the ceramic-metal interface (Figure 2, a-d) shows an eutectic microstructure with two phases, one Ag-rich (light contrast) and another Cu-rich (dark contrast). In all cases a continuous reaction layer free of pores and other defects was obtained, due to the good wettability of these alloys onto SiC ceramics [14]. 


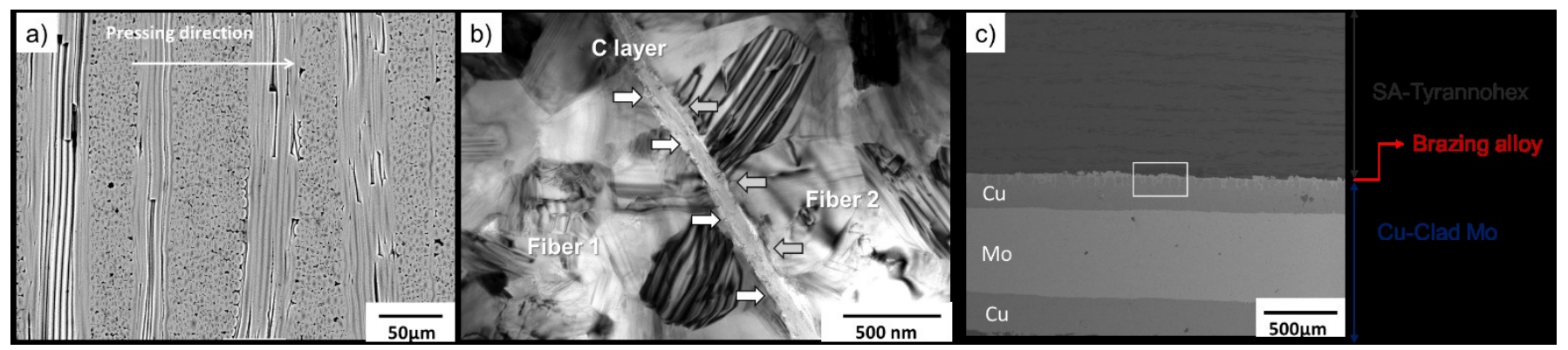

Figure 1. a) SEM micrograph of the fiber-bonded ceramic, b) transmission electron microscope image of the interface between two fibers, c) low magnification SEM micrograph of the ceramic joined to $\mathrm{Cu}$-clad-Mo (the white rectangle depicts the schematic location of the micrographs in Figure 2).

To better determine the reaction products, EDS maps were obtained (Figure 2-e) at the ceramicalloy interface. As is readily observed, Ti is concentrated near the ceramic surface, which can be attributed to the formation of TiC by reaction with the ceramic's outer carbon layer. These results are comparable to joints of fiber bonded ceramics to themselves using Cusil-ABA [4].

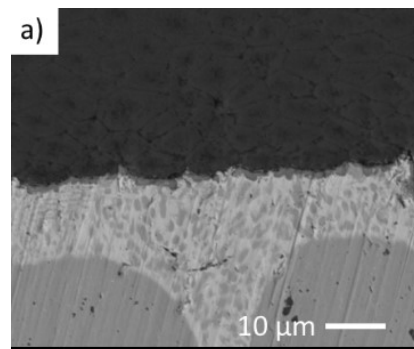

b)

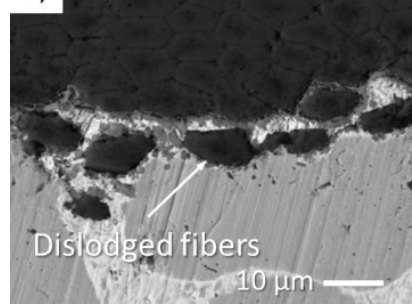

c)

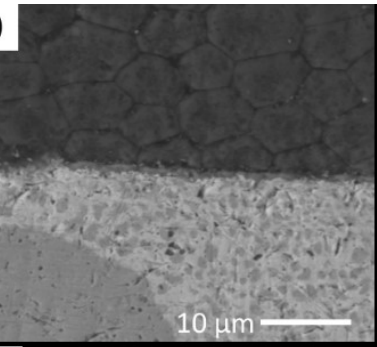

d)

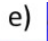

Si

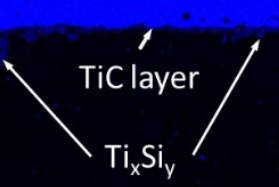

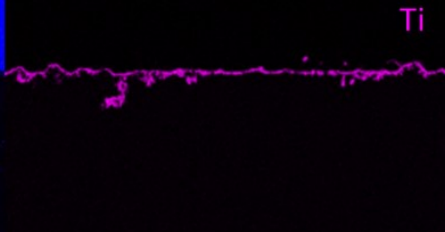

Figure 2. SEM micrographs of the ceramic-alloy interface from SiC/Cusil-ABA/Cu-clad-Mo obtained for: a) and b) $t_{B}=10 \mathrm{~min}$; c) and d) $t_{B}=20 \mathrm{~min}$. e) Si, Ti, C and Ag EDS compositional maps from the region in panel $\mathrm{d}$ ).

The preferential segregation of Ti at the ceramic/braze interface is consistent with the significant chemical affinity of Ti towards C; the carbide formation at the interface is helpful in promoting wetting and bonding. The TiC layer is continuous and homogeneous, as shown in Figure 2-e; this 
aspect is beneficial for the joint soundness, since the spreading and the wettability of the brazing alloy are uniform on the mating surfaces. Additionally, the preferential segregation of Ti near the composite surface and the subsequent TiC formation occurs regardless of the fiber orientation. Some titanium silicides also form underneath the TiC reaction layer, as can be seen from EDS maps.

Main results of the thermal conductivity of the fiber-bonded SiC material studied in this work are presented in Figure 3-a, including data from polycrystalline $\beta$-SiC [12]. SiC thermal conductivity decreases with temperature, as is the case in ceramics when conductivity is dominated by phonon scattering. Since grain boundaries also act as phonon scatterers, small grained SiC materials will exhibit lower thermal conductivities. In our case, grain size is in the range $d \sim 200-500 \mathrm{~nm}$ and thermal conductivity is in the range of CVD grown $\beta$-SiC polycrystals with grain sizes $c a .3 \mu \mathrm{m}$. The high thermal conductivity observed for its grain size can be attributed to the presence of highly aligned turbostratic carbon at the fibers' interfaces (Figure 1-b).

Conductivities of $\mathrm{Cu}$-Clad-Mo, fiber-bonded ceramic and the ceramic/Cusil-ABA/Cu-Clad-Mo joints are depicted in Figure 3-b. When considering conductivity, the joint can be described as three layers in series (metal, bonding alloy, and ceramic,) with different thicknesses $x_{m}, x_{a}$ and $x_{c}$ respectively. Joint conductivity can be described then as a function of each material's conductivity as [15]:

$$
k_{\text {joint }}=\frac{x_{m}+x_{a}+x_{c}}{\frac{x_{m}}{k_{m}}+\frac{x_{a}}{k_{a}}+\frac{x_{c}}{k_{c}}}
$$

Using the previous equation, we have estimated the expected thermal conductivity of the joints and plotted the results alongside the measurements. The good agreement between the rule of mixtures' prediction and the experimental values when accounting for experimental uncertainty indicates that no significant interfacial thermal resistance is present in the joint. 

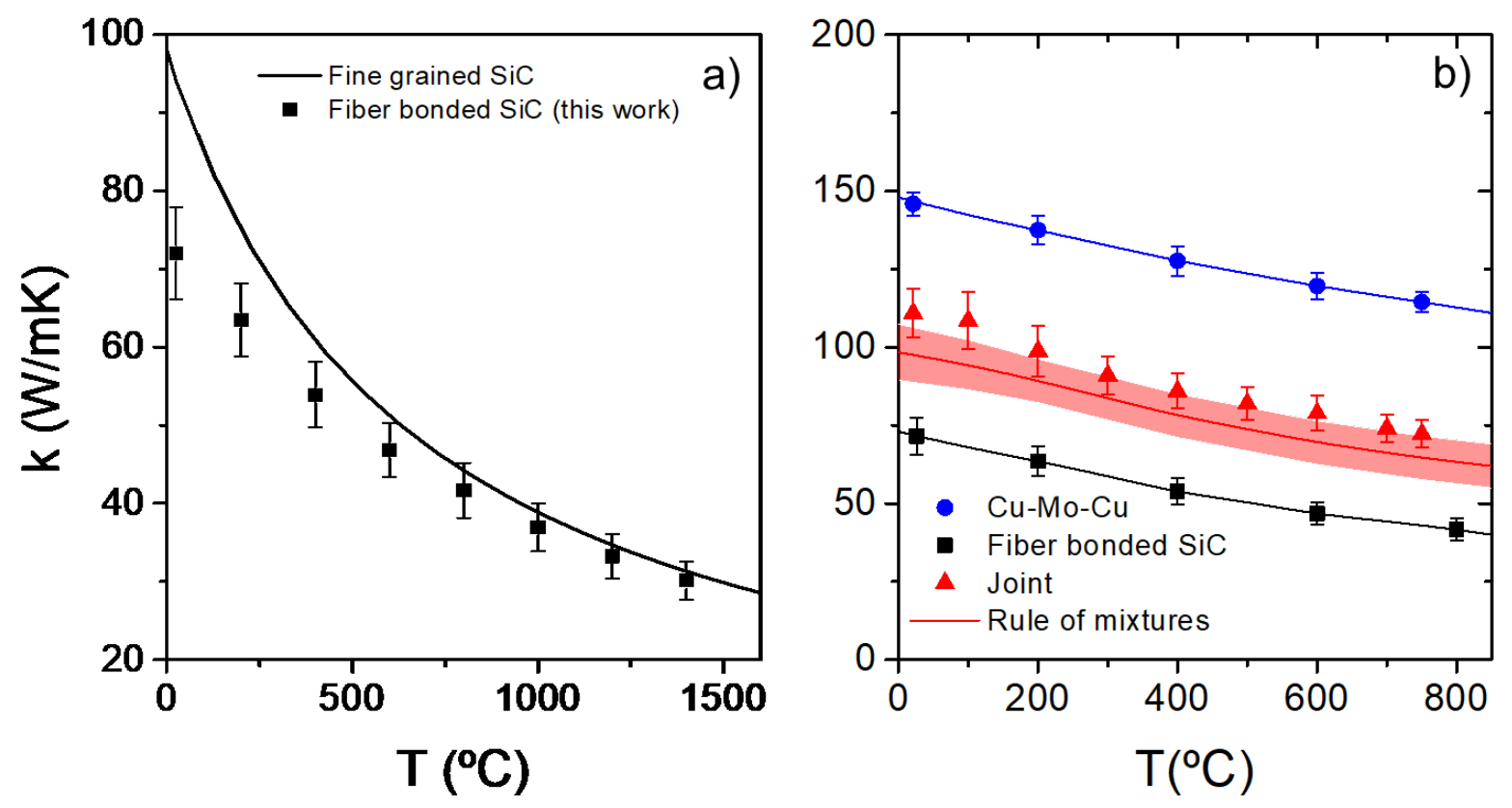

Figure 3. a) Measured in-plane thermal conductivity for fiber-bonded SiC, including data for $\beta$-SiC [12]. b) Thermal conductivity as a function of temperature for $\mathrm{Cu}$-clad-Mo, fiber bonded $\mathrm{SiC}$ and the joint. The solid line represents the rule of mixtures, while the shaded band shows the related uncertainty.

\section{Conclusions}

We have successfully joined fiber-bonded SiC ceramics to $\mathrm{Cu}$-clad-Mo using an Ag-Ti-Cu based brazing alloy. A brazing temperature of $900{ }^{\circ} \mathrm{C}$ for $10-20$ min results in a sound joint regardless of orientation. The reaction layer is 1-2 $\mu \mathrm{m}$ thick and free of pores and defects. Ti migrates towards the ceramic side of the joint to form a TiC layer, while a eutectic microstructure of Ag and $\mathrm{Cu}$ forms the bulk of the joint.

The thermal conductivity across the joint was found to be consistent with the metal and ceramic being in series with no significant interfacial resistance. The joint is highly conductive and forms an almost perfect thermal interface between the two materials, confirming the quality of the obtained brazing layer. 


\section{Acknowledgements}

Part of this research was funded by the Spanish MINECO under grant MAT2016-76526-R. Electron microscopy measurements were performed at the CITIUS central services of the University of Seville. Carmen Vera gratefully acknowledges support of the FPU program of the Spanish Ministerio de Educación, Cultura y Deporte.

\section{References}

[1] S. Kajii, T. Ishikawa, K. Matsunaga, Y. Kohtoku, A new type of fiber-bonded-ceramic material synthesized from pre-oxidized Si-Ti-C-O fiber, Adv. Perform. Mater. 1 (1994) 145-155. https://doi.org/10.1007/BF00713728.

[2] T. Ishikawa, S. Kajii, K. Matsunaga, T. Hogami, Y. Kohtoku, T. Nagasawa, A tough, thermally conductive silicon carbide composite with high strength up to $1600^{\circ} \mathrm{C}$ in air, Science (80-. ). 282 (1998) 1295-1297. https://doi.org/10.1126/science.282.5392.1295.

[3] M. Ferraris, M. Salvo, V. Casalegno, S. Han, Y. Katoh, H.C. Jung, T. Hinoki, A. Kohyama, Joining of SiC-based materials for nuclear energy applications, in: J. Nucl. Mater., North-Holland, 2011: pp. 379-382. https://doi.org/10.1016/j.jnucmat.2010.12.160.

[4] M. Singh, T. Matsunaga, H.T. Lin, R. Asthana, T. Ishikawa, Microstructure and mechanical properties of joints in sintered $\mathrm{SiC}$ fiber-bonded ceramics brazed with $\mathrm{Ag}-\mathrm{Cu}$-Ti alloy, Mater. Sci. Eng. A. 557 (2012) 69-76. https://doi.org/10.1016/j.msea.2012.05.110.

[5] M. Singh, R. Asthana, Joining of ZrB2-based ultra-high-temperature ceramic composites to $\mathrm{Cu}$-Clad-Molybdenum for advanced aerospace applications, Int. J. Appl. Ceram. Technol. 6 (2009) 113-133. https://doi.org/10.1111/j.1744-7402.2008.02291.x.

[6] M. Singh, C. Smith, R. Asthana, A. Gyekenyesi, Integration of high-conductivity graphite foam to metallic systems using Ag-Cu-Ti and Ag-Cu-Pd braze alloys, Int. J. Appl. Ceram. Technol. 10 (2013) 790-800. https://doi.org/10.1111/ijac.12123.

[7] M. Singh, R. Asthana, T.P. Shpargel, Brazing of carbon-carbon composites to Cu-clad molybdenum for thermal management applications, Mater. Sci. Eng. A. 452-453 (2007) 699-704. https://doi.org/10.1016/j.msea.2006.11.031.

[8] A. Luedtke, Thermal Management Materials for High-Performance Applications, Adv. Eng. Mater. 6 (2004) 142-144. https://doi.org/10.1002/adem.200300552.

[9] G. Jiang, L. Diao, K. Kuang, G. Jiang, L. Diao, K. Kuang, Properties of $\mathrm{WCu}, \mathrm{MoCu}$, and $\mathrm{Cu} / \mathrm{MoCu} / \mathrm{Cu}$ High-performance Heat Sink Materials and Manufacturing Technologies, in: Adv. Therm. Manag. Mater., Springer New York, 2013: pp. 73-87. https://doi.org/10.1007/978-1-4614-1963-1_5. 
[10] P.J. Grobner, Determination of physical and mechanical properties of copper-clad molybdenum sheet, 1988. https://doi.org/10.2172/7048768.

[11] H. Mizuhara, E. Huebel, T. Oyama, High-reliability joining of ceramic to metal, Am. Ceram. Soc. Bull. 68 (1989) 1591-1599. https://www.osti.gov/biblio/7035093 (accessed March $17,2020)$.

[12] L.L. Snead, T. Nozawa, Y. Katoh, T.S. Byun, S. Kondo, D.A. Petti, Handbook of SiC properties for fuel performance modeling, J. Nucl. Mater. 371 (2007) 329-377. https://doi.org/10.1016/j.jnucmat.2007.05.016.

[13] M. Singh, R. Asthana, Characterization of brazed joints of C-C composite to Cu-cladMolybdenum, Compos. Sci. Technol. 68 (2008) 3010-3019. https://doi.org/10.1016/j.compscitech.2008.06.012.

[14] J.H. Xiong, J.H. Huang, H. Zhang, X.K. Zhao, Brazing of carbon fiber reinforced SiC composite and TC4 using Ag-Cu-Ti active brazing alloy, Mater. Sci. Eng. A. 527 (2010) 1096-1101. https://doi.org/10.1016/j.msea.2009.09.024.

[15] A. Öchsner, G.E. Murch, Heat transfer in multi-phase materials, Springer, 2011. 